\title{
Exploring The Relationship Between Emotional Intelligence And Academic Stress Among Students At A Small, Private College
}

Chad Stevens, Keystone College, USA

Elizabeth Schneider, Keystone College, USA

Patricia Bederman-Miller, Keystone College, USA

Karen Arcangelo, Keystone College, USA

\begin{abstract}
This research explored the relationship between total-trait emotional intelligence and academic stress among college students at a small, private college. Student total-trait emotional intelligence (TTEI) and university stress scores were significantly correlated. Measures of TTEI and USS are useful for student intervention to impact issues such as attrition. To increase retention, small private colleges benefit significantly from knowing students' level of academic stress and emotional intelligence. Identifying specific factors and mitigating the adverse effects of these factors allows small colleges the opportunity to provide additional services for students.
\end{abstract}

Keywords: Stress; Emotional Intelligence; Attrition, College

\section{INTRODUCTION}

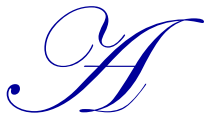

bout 20 million students were projected to enroll in higher-education institutions to 2018 (NCES, 2009). About one-third of students do not return to college in their sophomore year (U.S. News, 2019). Different factors impact the decision to remain at college. Many small, private colleges are financially driven mostly by tuition. Attrition is a reduction in student enrollment (Simpson, 2004). Attrition is especially important to non-profit, private small colleges. The average four-year graduation rate at less-selective, small colleges is about $27 \%$ (Gansemer-Topf, Zhang, Beatty, \& Paja, 2014, pg. 3). Many students may attrite because of academicrelated distress and poor coping skills.

Today small, private colleges have fewer numbers of students available in the applicant pool (Barshay, 2018). Ensuring admitted students remain enrolled is critical to the financial viability of these schools. Any one predictor does not completely explain and contribute to college student attrition (Yanaguria, 2012). Several factors possibly contributing to college student attrition are levels of student stress and levels of student emotional intelligence.

\section{Rationale}

Small, private colleges would benefit significantly from knowing the specific level of student academic stress and student emotional intelligence. Small private colleges need to retain students. Identifying specific factors and mitigating the adverse effects of these factors allows small colleges the opportunity to provide additional services for students and helps colleges retain students. If particular factors such as emotional intelligence and academic stress level among college students were identified and understood, colleges might retain more students, remaining viable. 


\section{Theoretical Framework}

The theoretical perspectives and models for this research are grounded in Cognitive Appraisal and Tinto's Theory of Departure. Cognitive appraisal examines how a person's experience of emotion (affect-related traits) and perceived stress is often determined by how the person considers or evaluates circumstances and events (Lazarus, 1991).

Tinto's Theory of Departure identifies three primary causes of student departure from higher learning: academic struggles, students' incapability to accomplish educational goals, and students' inability to acclimate socially to the collegiate environment (Tinto, 1975, pg. 76).

\section{Trait-Emotional Intelligence}

Traits are relatively stable aspects of personality impacting behavior and involve emotion-related natures and selfperceptions. Trait-EI is a general indicator of emotional functioning. Trait-EI is negatively related to stress, turnover, and maladaptive coping. Trait-EI addresses the subjectivity of emotion-related natures and self-perceptions (Petrides, 2009). Personality refers to differences in one's patterns of thinking, feeling, and behaving related to, for example, sociability or irritability (APA, 2019).

In this study total-trait EI (TTEI) was the global (total) score based on outcomes of the Trait-Emotional Intelligence Questionnaire- Short Form (TEIQue-SF). The TEIQue-SF primarily measures global (total) trait-EI providing a picture of emotional functioning, capacity to manage affiliations, expressive control, and response to stress distinct from human cognitive ability (Thomas, 2018; Siegling, Ashley, Vesely, Petrides \& Saklofske, 2015). Additionally, the TEIQue-SF has four lower-level personality factors, including well-being, sociability, selfcontrol, and emotionality (Siegling et al. 2015).

\section{Academic Stress}

There are many different types of stress. This study focused on generalized feelings and severity of academic stress. Extreme stress and poor coping skills put college students at risk (Stallman \& Hurst, 2016). Psychological symptoms of stress are often accompanied by physical ailments such as raised blood pressure, as well as feelings of tension and nervous thoughts. The University Stress Scale (USS) is a self-reporting instrument measuring levels of academic stress a college student experiences and the intensity of academic stress a college student experience. The USS contains 21 general items from which a college student identifies the severity of academic-related stress experienced during the prior month. The USS score indicates the level of academic stress a college student experiences (Stallman \& Hurst, 2016).

\section{Purpose}

The purpose of this research is to explore the relationship between total-trait emotional intelligence and academic stress among college students at a small, private college.

\section{Research Questions}

1. Is there is a relationship between total-trait emotional intelligence and academic stress among college students at a small, private college?

2. How does TTEI score compare between first, second, third, and fourth-year students?

3. How does the level of academic stress compare between first, second, third, and fourth-year students?

4. How does gender impact TTEI?

5. How does gender impact the level of academic stress?

\section{Hypotheses}

Hypothesis: There is a relationship between total-trait emotional intelligence and academic stress among college students at a small, private college. 
Null Hypothesis: There is not a relationship between total-trait emotional intelligence and academic stress among college students at a small, private college?

\section{Definitions}

Total-Trait Emotional Intelligence. TTEI is a measure/score of global (total), trait-emotional intelligence consisting of well-being, self-control, emotionality, and sociability (Petrides, 2009).

University Stress. USS is a measure/score of academic stress experienced by college students and the intensity of the academic stress experienced by college students (Stallman, 2016).

\section{Delimitations}

There were delimitations in this research to narrow and consciously control the factors. Instruments were purposely chosen. The distribution of forms through individual classes at a singular private college was a delimitation. Only students attending this college and taking specific courses were selected to participate in the research. The chosen method of distribution saved time and provided convenience for both the researchers and participants.

\section{Limitations}

There were limitations to this research due to available resources. Since the sample is non-random and purposive and confined to one college, generalization is a concern. The sample size, distribution of surveys, and demographic restrictions impacted the power of the results. The time of the semester/academic year the surveys were administered was also a limitation. College students may experience stress differently at different times of the academic year.

\section{Significance of the Study}

If total-trait emotional intelligence (TTEI) and university stress scores (USS) of students correlate, TTEI and USS may be used for student intervention, possibly impacting issues such as attrition; mutually benefitting institutions of higher learning and college students. Institutions could provide college students with needed services to manage stress and remain at college. Colleges and universities would gain the opportunity to improve student outcomes and institutional finances. The results of this study potentially impact countless small colleges and college students.

\section{LITERATURE REVIEW}

\section{Emotional Intelligence}

Research exists on emotional intelligence (EI). There are several EI models developed by different researchers. BarOn's (2006) model focuses on emotional intelligence, cognitive intelligence, and the relationship to overall intelligence (Bar-On, 2006). Salovey and Mayer (1997) are known for the ability-based model of EI. Ability-based models are more objective and frame EI as an intelligence. EI allows a person the ability to accurately reason based on emotion. Furthermore, EI recognition and knowledge improve thought processes. Goleman (1995) used a mixedmethod model to explain EI based on a competency instrument, in addition to an appraisal instrument.

It is argued EI cannot be measured as a 'mental ability.' EI is not a cognitive intelligence, but a subjective appraisal of emotions (Petrides, 2009). Trait-based models of emotional intelligence recognize the subjectivity of emotional perceptions relating to well-being, self-control, emotionality, and sociability (Petrides, 2009; Mikolajczak, Olivier, Leroy, \& Roy, 2007). Personality, based on self-perception, is the basis of Petride and Furnham's (2006) research. Trait EI application may allow for explanations and predictions of emotional self-efficacy in many different contexts.

\section{Stress}

Homeostasis. Research on stress and coping is well documented. Homeostasis is self-regulation of the body and maintaining physiological equilibrium. Cannon suggested human bodies reacted to external threats by changing 
internally. A person's body escapes illness by maintaining balance. This approach to stress was predominantly physiological in nature (Cannon, 1914, 1928).

Appraisal. Richard Lazarus believed different people react to situations in different ways resulting in different outcomes and examined the relationship between the stressor and individual reaction to the stressor. Psychologists began to investigate stress and coping based on perceptions and the subjective way individuals view personal environments. Lazarus and others believed understanding cognitive mediation was the root of understanding psychological stress. Lazarus finds the term perception restrictive and chooses to use the term appraisal instead. Lazarus (1999) believes in primary and secondary appraisals. Primary appraisal is the importance of the perceived stressor to the individual, and secondary appraisal focuses on control. Lazarus believes stress is secondary to emotion, and understanding emotions are integral to understanding stress.

Defining stress is highly subjective without one definition. Physiological stress is the human body's physical response due to external factors or stressors/stimuli (heat, cold, isolation, etc.). Psychological Stress is a mental response or creation through perception, influencing one's thought and perceived reality resulting in change, either physical or mental, within the human body. Academic stress is associated with college.

\section{Emotional Intelligence (EI) and Academics}

Emotional intelligence is the subject of substantial scholarly research. Despite the concept's central place in psychological research, the possible link between emotional intelligence and attrition is not extensively studied. While recent studies (Garg et al. 2016, pg. 1) examined the correlation between individuals' levels of emotional intelligence and impact on post-secondary academic achievement, such studies considered only the role of emotional intelligence in students remaining in school, thus, failing to consider the concept's effect in deterring students from finishing secondary education.

Garg et al. (2016) concluded emotional intelligence was not directly related to academic achievement (pg. 4). However, emotional intelligence was linked directly with adjustment to university; adjustment to university was then directly linked to first-year grade point average (GPA). This study surveyed two-hundred and ninety-nine first-year students attending Laurentian University. The surveys were distributed through a first-year psychology course to students of multiple majors (Garg et al. 2016, pg. 4). The surveys distributed included Bar-On Emotional Quotient Inventory (EQ-i) and the Student Adaptation to College Questionnaire (SACQ). Overall, the findings concluded emotional intelligence significantly influenced adjustment to university, affecting academic achievement (Garg et al. 2016, pg. 5).

In contrast to the single-variable study conducted by Garg et al. (2016), Buvoltz, Solan, and Longbotham (2008, pg. 2) examined the correlation between attrition and multiple psychological characteristics, including emotional intelligence. In this study, the relationship between EI, learner autonomy, and retention was examined in an accelerated undergraduate degree completion program. The sample of this study consisted of one hundred and twenty-nine students at a small, private, liberal arts college. The sample of students was contacted by email and multiple surveys were used to measure the variables. The study found no correlation between the variables EI and retention, however partial correlation was found between EI, learner autonomy, and retention when considered simultaneously.

Evidence emotional intelligence is enhanced through age and training programs is supported in the literature (Buvoltz et al. 2008, pg. 2). Entering college, many first-year students experience new situations and make choices (Buvoltz et al. 2008, pg. 1). The ability to cope with different social situations and making the best decisions in these situations is a measure of one's emotional intelligence. The fact first-year students uniquely exposed to a greater number of challenges requiring the use of EI in a short period of time, as well as, the fact first-year students of every university yield the highest attrition rates of the student population, necessitated investigation into the relationship between EI and attrition (DeBerard, Spielmans, \& Julka, 2004, pg. 3) Such an investigation was undertaken by Yarrish and Law (2009). The purpose of the study was to determine the differences of EI among different majors at a small, liberal arts college. The sample in the study included sixty-six first year business students in an introductory business course. The instrument was a self-reporting survey distributed in class. The findings of this study found all disciplines needed enhancement in certain areas of emotional intelligence. 
Siegling, Furnham, and Petrides (2015) completed a study among undergraduate students. The study specifically examined the relationship between TTEI, the Big Five personality traits, and gender. The results indicated genderspecific relationships among TTEI and the Big-Five personality traits varied.

\section{Stress and Academics}

College students are stressed (Bhujade, 2017, p. 750). There are few studies quantifying levels of stress or effects of stress on college students. A seminal study examining the relationship between stress and college students was conducted by Towbes and Cohen (1996). They assessed the effect of chronic stress on college students and defined two types of chronic stress. The first type of chronic stress is caused by a single event creating difficulty beyond that point in time. An example is failing a test and trying to raise the grade for the rest of the semester. The second type of chronic stress is caused by a difficult continuing time, such as chronic pain. Both types of stress are considered in the study. Freshman students had a higher stress score and were anxious about choosing a major, missing home, and missing distant friends. The focus here was on the identified stressor and not the perception of stress.

Another study examined stress in college students was completed by Dusselier et al. (2005). The purpose of this study was to determine contributing factors of stress in college students living in residence halls. It was found depression, anxiety, chronic illness, and sleep difficulties significantly predicted stress. Different years in school also perceive stress differently; sophomores experience higher levels of stress when compared to other years in college.

Stress also causes several maladies if serious and prolonged enough. In a cross-institutional study, stress the number one worry of college students; closely followed by body image, AIDS, physical fitness, and cancer. A malady often caused by prolonged stress is depression (Bhujade, 2017, p. 750). The study identified stress as very common in college students. Forty-three percent of students felt extremely depressed and sixteen percent thought life was pointless and not worth living for (Bhujade, 2017, p. 750).

Another study examined life events, life strains, and coping behaviors of college students distressed and non-stressed. The subjects consisted of 451 students given the General Health Questionnaire (GHQ) (which divided them into distressed and non-distressed categories), and life events and life strains inventories. The results revealed 21.36 percent of students were distressed. The distressed students experienced a significant increase in adverse life events (Zeena, Rao, Rao, Subbakrishna \& Prabhu, 1990).

\section{METHODOLOGY}

\section{Research Design}

This study is quantitative, non-experimental, exploratory survey research. The variables in this study are total-trait emotional intelligence and academic stress.

\section{Sample}

The non-random sample for the study included college students at multiple levels attending a small, private college. Students' primary fields of study included a variety of disciplines. An initial sample of just over two hundred students was contacted to participate in this research. After eliminating duplicates and surveys with missing responses, the sample size was 134 participants $(\mathrm{N}=134)$. Of these, $47.8 \%$ were female; $52.2 \%$ male. The majority $(95.5 \%)$ indicated they were full-time students. The breakdown for grade level was as follows: $26.1 \%$ freshmen, $12.7 \%$ sophomore, $23.9 \%$ junior, and $37.3 \%$ senior. About $78 \%$ indicated they were Caucasian. 


\section{Instrumentation}

TEIQue-SF. Petrides (2009) explains the TEIQue-SF measures global trait emotional intelligence. The TEIQue is robust, providing an overall measure of emotional control and response to pressure (Thomas, 2018). In addition, four subscales; well-being, self-control, emotionality, and sociability result from deduction scoring based on the full form inventory (Psychometriclab.com, 2018). The TEIQue-SF measures how well students understand, manage, interpret, and use personal emotions and emotions of others. The assessment also evaluates how students react to pressure, self-motivate, and adapt (Thomas, 2018).

Reliability and Validity. TEIQue scores were universally normally distributed and reliable. There is evidence of convergent/discriminant validity. There is also evidence of criterion validity, with TEIQue scores predicting depression, anxiety, and future state affectivity and emotional reactivity in neutral and stressful situations. TEIQue shows incremental validity to predict emotional reactivity (Mikolajczak et al. 2007). Explanatory Factor Analysis for construct validity revealed a four-factor measure scale with 20 items (well-being, self-control, emotionality, and sociability). The scale was tested with Confirmatory Factor Analysis resulting in good fit. The internal consistency score was .81 and test-retest reliability was .86. Results indicate TEIQue is a valid and reliable instrument (Denz, Azer, \& Iayak, 2013; Cooper \& Petrides, 2010).

Scoring. The TEIQue-SF is a 30-item questionnaire (based of full form) measuring global trait emotional intelligence. The TEIQue-SF uses a Likert-type scale (1- completely disagree to 7- completely agree) with a theoretical average of 3.5. The global trait EI score was calculated by summing item scores and dividing by the total number of items (Petrides, 2009).

USS. The USS provides a total academic stress score making the instrument a useful measure for researchers working with college students. The USS provides a measure of academic stress experienced by college students, as well as, the overall intensity of the stress experienced by college students (Stallman \& Hurst, 2016).

\section{Reliability and Validity.}

The scale demonstrates good internal consistency (Cronbach's alpha $\alpha=.83$ ).

The correlation between the first administration of the USS and the second administration of the USS was .82 (95\% CI .79 - .85), showing respectable test-retest reliability (Stallman \& Hurst, pp. 10-11, 2016).

\section{Scoring.}

To determine a clinical cut-off level (Extent score $\geq 13$ predicts significant psychological distress) of stress indicative of psychological problems on the USS, a receiver operator characteristic (ROC) curve methodology was used, with greatest sensitivity and specificity on the University Stress Scale compared to the clinical cut-off recommended on the K10 for university students. The positive predictive value of the test was $84.20 \%$ and negative predictive value of the test was $53.83 \%$ on psychological distress (Stallman \& Hurst, pp. 10-11, 2016).

\section{Procedure}

A demographic questionnaire, the Total-Trait Emotional Intelligence Questionnaire-Short Form (TEIQue-SF) inventory, and University Stress Scale (USS) instrument were distributed to varied levels of college students at a small private college. The surveys were given to multiple classes throughout multiple disciplines to eliminate bias. The data was collected from the completed surveys and analyzed to determine relationships among variables.

\section{Analyses of Data}

The demographic questionnaire, TEIQue-SF and USS were used to collect data from participants. The data was analyzed using SPSS 25 to determine if a relationship existed between total-trait emotional intelligence scores and academic stress levels of college students. 


\section{RESULTS}

A Pearson's correlation was run between the USS scores and TTEI scores among participants. A moderate negative correlation between the two variables was found $(\mathrm{n}=134, \mathrm{r}=-.448, \mathrm{p}<.01)$. Thus, there is enough evidence indicating a moderate negative correlation exists between the amount of academic stress students exhibit and student traitemotional intelligence (more stress indicates lower emotional intelligence).

After running a t-test between male and female students, there was no significant difference in the global trait EI score $[\mathrm{t}(132)=1.473, \mathrm{p}=.143]$. However, a significant difference was found in average academic stress (USS) between male and female students $[\mathrm{t}(132)=-2.176, \mathrm{p}=.031]$. Also, both male and female students were above the "13" cutoff for USS thus indicating a high degree of academic stress (Extent score $\geq 13$ predicts significant psychological distress). The female student average was higher for academic stress; the male student number higher for trait emotional intelligence.

A One-Way ANOVA was run among the four grade levels (freshmen, sophomore, junior, and senior) to test for a significant difference in academic stress and trait emotional intelligence. A significant difference was found among the four grade levels for trait emotional intelligence $[F(3,130)=4.674, p=.004]$, however no significant difference in academic stress was found among the four grade levels $[F(3,130)=.241, \mathrm{p}=.868]$. After running a Bonferroni post hoc test for trait emotional intelligence, a significant difference was found between sophomore and seniors and between the freshmen and seniors.

\section{DISCUSSION}

Results indicate a moderate inverse relationship between trait-emotional intelligence and perceived academic stress among participants supporting our hypothesis.

Students reported varying levels of emotional control and response to pressure relating to well-being, self-control, emotionality, and sociability. Students also reacted to pressure, self-motivation, and adaption at varying levels, indicating concerns about how well students understand, manage, interpret, and use emotions. Student perceptions of emotional self-efficacy and emotional functioning are stable aspects of personality impacting behavior. Trait- emotional intelligence is negatively related to stress and maladaptive coping possibly resulting in attrition. This information is potentially useful for institutions of higher education in identifying students at risk and providing students with programs and support to remain in school.

Students reported varying levels of generalized feelings and severity of academic stress. College students are at risk of experiencing symptoms of stress including physical ailments, feelings of tension, and nervous thoughts, possibly impacting the ability to function and remain in the college environment. This information is useful for institutions of higher education in identifying students at risk and providing students with programs and support to remain in school.

Research results support prior studies indicating a generally high level of academic stress among college students, as most of the students' self-reported high levels of academic stress. Students with higher levels of stress may have difficulty adjusting to college and remaining in college due to the stresses of academic life. Students with higher levels of total-trait emotional intelligence are generally more self-confident, happy, and sociable (Petrides, 2009). Our results suggest the greater the trait-emotional intelligence, at least to some degree, the better the ability to handle the stress of academic life. The number of students studied and the time in the semester of data collection possibly impacted results. Replication of these results is necessary in a future study.

Our results showed student scores of total-trait emotional intelligence in first, second, third, and fourth year of study were significantly different. Fourth-year students, as a group, had a higher total-trait emotional intelligence score than first-year students. While results do not specifically indicate why this was the case, perhaps college experience, like work experience (Shipley, Jackson, \& Seacrest, 2010), helps one develop trait-emotional intelligence. Future longitudinal research may confirm the difference in total-trait emotional intelligence among students in different years of study. 
Our study examined a relationship between gender and student total-trait emotional intelligence, and also gender and level of academic stress. Results indicated no significant difference in total-trait emotional intelligence between males and females; however, there was a difference in the level of academic stress experienced between males and females. Although females reported a higher level of academic stress, both males and females reported a level of stress above the cut-off, indicating all were under a high degree of academic stress. One factor to consider again is the timing of questionnaire administration.

\section{RECOMMENDATIONS}

The TEIQue-SF and USS may provide pathways for interventions to further develop students in several ways. We know attrition is a serious problem for colleges. If students with low total-trait emotional intelligence are identified early in their academic career, colleges may provide students with resources, allowing students to better cope with the stresses of college. Increased levels of persistence may result benefitting both the student and institution.

Further study is needed to replicate results at various times during the academic year. Other factors to possibly consider include age, transfer-students, first-generation college students, and academic performance (GPA) as these factors may relate to emotional intelligence, academic stress, and the student's likelihood to persist in college.

\section{CONCLUSION}

The purpose of this study was to explore the relationship between trait-emotional intelligence and academic stress among students at a small, private college. A moderate negative correlation was found between the amount of academic stress students exhibit and student trait- emotional intelligence. A significant difference was found in average academic stress (USS) between male and female students. A significant difference was also found among the four grade levels for trait emotional intelligence. Evidence suggests these variables are important to the understanding of student retention issues. We hope the results obtained from this study and future studies allow small private colleges the tools to measure the predictive validity of total-trait emotional intelligence and academic stress impacting attrition.

\section{ACKNOWLEDGEMENTS}

Portions of this paper were presented at the 2019 Clute International Academic Conferences Denver. We would like to thank Keystone College student, Ms. Madeline Moro, for her significant contribution to this project.

\section{AUTHOR BIOGRAPHIES}

Dr. Stevens has over 25 years of academic and professional experience. He teaches management/administration, organizational behavior, research methods, and marketing courses. His research focuses on variables including emotional intelligence, cognitive/affective behavior, stress and coping, turnover, leadership styles, and awareness/preparedness in business/professional settings. His research led to the creation of a research variable; personal-career turnover (PCT). E-mail: chad.stevens@keystone.edu

Attorney Elizabeth Schneider has over 30 years of private practice as a business lawyer in Pennsylvania. She is currently a full-time faculty member at Keystone College and continues to maintain a small private business practice. She teaches Business Law, Business Ethics, Business Capstone, Conflict Management, Sports Law, and Employment Law. She also has an MBA with a concentration in conflict management. Her research interests lie primarily with litigation avoidance and effective conflict management and resolution in business and education. Attorney Schneider teaches both undergraduate and graduate students in traditional face to face and online classes. E-mail: elizabeth.schneider@keystone.edu

Dr. Bederman-Miller has over 40 years of teaching experience in high school and college. Most of her career was spent at the college level, teaching various mathematics courses, from basic math skills through Statistics and Research. Her research includes topics such as math anxiety, student grade perception, global citizenship, exploration of healthy eating of college students, and Supplemental Instruction (SI). Some of her current research involves faculty 
evaluations and online versus face-to-face statistics classes. Dr. Miller was the recipient of the 2005 Margaretta Belin Chamberlin Chair for Distinguished Faculty Service at Keystone College. E-mail: pat.miller@keystone.edu

Dr. Karen Arcangelo holds an MS and Ph.D. in School Psychology from Syracuse University. She is a certified school psychologist and currently teaches undergraduate and graduate courses in psychology, education and special education. Her interests include the development of self-regulation skills, online pedagogy, family engagement and autism spectrum disorder. She has presented at various workshops, trainings and state conferences regarding these topics. E-mail: karen.arcangelo@keystone.edu

\section{REFERENCES}

APA. (2019). American psychological association: Personality. Retrieved from https://www.apa.org/topics/personality/

Bar-On, R. (2006). The Bar-On model of emotional-social intelligence. Psicothema, 18, supl., 13-25.

Barshay, J. (2018). Colleges set to fight for fewer students. U.S.News \& World Report. Retrieved from https://www.usnews.com/news/education-news/articles/2018-09-10/colleges-set-to-fight-for-fewer-students

Bhujade, V. M. (2017). Depression, anxiety and academic stress among college students: A brief review. Indian Journal of Health and Wellbeing, 8(7), 748-751.

Buvoltz, K. A., Powell, F. J., Solan, A. M., \& Longbotham, G. J. (2008). Exploring emotional intelligence, learner autonomy, and retention in an accelerated undergraduate degree completion program. New Horizons in Adult Education \& Human Resource Development, 22(3), 26-43

Cannon, W. (1914). The interrelations of emotions as suggested by recent physiological researchers. American Journal of Psychology, 25, 256-82.

Cannon, W. (1928). The mechanism of emotional disturbance of bodily functions. New England Journal of Medicine, 198, 877-84. The American Journal of the Medical Sciences, 189, 1-14.

Cooper, A. \& Petrides, K. V. (2010). A psychometric analysis of the Trait Emotional Intelligence QuestionnaireShort Form (TEIQue-SF) using Item Response Theory. Journal of Personality Assessment, 92, 449-457.

DeBerard, S. M., Spielmans, G. I., \& Julka, D. C. (2004). Predictors of academic achievement and retention among college freshmen: A longitudinal study. College Student Journal, 38(1), 66-80. Retrieved March 2, 2018.

Denz, M., Azer, E., \& Iayak, E. (2013). Trait emotional intelligence questionnaire-short form: Validity and reliability studies. Egitim ve Bilim. 38. 407-419.

Dusselier, L., Dunn, B., Wang, Y., Shelley, Mack C...II, \& Whalen, D. F. (2005). Personal, health, academic, and environmental predictors of stress for residence hall students. Journal of American College Health, 54(1), $15-24$.

Gansemer-Topf, A., Zhang, Y., Beatty, C., \& Paja, S. (2014). Examining factors influencing attrition at a small private selective liberal arts college. Journal of Student Affairs Research and Practice, 51(3), 270-285. doi:http://dx.doi.org/10.1515/jsarp-2014-0028

Garg, R., Levin, E., \& Tremblay, L. (2016). Emotional intelligence: Impact on post-secondary academic achievement. Social Psychology of Education: An International Journal, 19(3), 627-642. doi:http://dx.doi.org/10.1007/s11218-016-9338-x

Goleman, D. (1995). Emotional intelligence. N.Y.: Bantam Books.

Lazarus, R. (1999). Stress and emotion: A new synthesis. London: Free Association Press.

Lazarus, R. (1991). Progress on a cognitive-motivational-relational theory of Emotion. American Psychologist, 46(8), 819-834.

Mikolajczak, M., Olivier, L., Leroy, C., \& Roy, E. (2007). Psychometric properties of the Trait Emotional Intelligence Questionnaire: Factor structure, reliability, construct, and incremental Validity in a FrenchSpeaking Population, Journal of Personality Assessment, 88:3, 338-353.

NCES. (2009): National Center for Education Statistics. Projections of Education Statistics to 2018, 37 th ed. Retrieved from https://nces.ed.gov/pubs2009/2009062.pdf

Petrides, K. V. \& Furnham, A. (2006). The role of trait emotional intelligence in a gender-specific model of organizational variables. Journal of Applied Social Psychology, 36, 552-569.

Petrides, K. V. (2009). Technical manual for the Trait Emotional Intelligence Questionnaires (TEIQue) ( $1^{\text {st }}$ edition, $4^{\text {th }}$ printing). London: Psychometric Laboratory. 
Psychometriclab.com. (2018). Obtaining the TEIQue. Retrieved from: http://www.psychometriclab.com/Home/Default/14

Shipley, N.L., Jackson, M.J. \& Segrest, S.L. (2010). The effects of emotional intelligence, age, work experience, and academic performance. Research in Higher Education Journal (9), 1-18.

Siegling, A., Furnham, A., \& Petrides, K. (2015). Trait emotional intelligence and personality: Gender-invariant linkages across different measures of the big-five. Journal of Psychoeducational Assessment. Vol.33 (I), $57-67$.

Simpson, S. (2004). A study of attrition in higher education with implications for supportive services. Theses, Dissertations and Capstones. Paper 171. Marshall University.

Salovey, P. \& Mayer, J. (1997). Emotional Intelligence. Imagination, Cognition, and Personality, 9, 185-211.

Siegling, A., Ashley K., Vesely, A., Petrides K., and Saklofske, D. (2015) Incremental Validity of the Trait Emotional Intelligence Questionnaire-Short Form (TEIQue-SF), Journal of Personality Assessment, 97:5, 525-535, DOI: 10.1080/00223891.2015.1013219

Stallman, H. M. \& Hurst, C. P. (2016). The University Stress Scale: Measuring domains and extent of stress in university students. Australian Psychologist, 51, 128-134

Thomas. (2018). TEIQUE-SF. Retrieved from https://www.thomasinternational.net/ensg/assessments/assessments-we-offer/teique-sf/

Tinto, V. (1975). Dropouts from higher education: A theoretical synthesis of recent literature. A Review of Educational Research, 45, 89-125.

Towbes, L. C., \& Cohen, L. H. (1996). Chronic stress in the lives of college students: Scale development and prospective prediction of distress. Journal of Youth and Adolescence, 25(2), 199.

Turnover and Retention. (2018, May 23). In Catalyst. Retrieved September 29, 2018, from https://www.catalyst.org/knowledge/turnover-and-retention

U.S. News. (2019). Education. Retrieved from https://www.usnews.com/best-colleges/rankings/nationaluniversities/freshmen-least-most-likely-return

Yanaguria, T. (2012). Attrition cost model instruction manual. Washington, D.C. American Institute for Research.

Yarrish, K. K., \& Law, M. D. (2009). An exploration on the differences in emotional intelligence of first year students examined across disciplines within the school of business in a liberal arts college. Contemporary Issues in Education Research, 2(4), 47-52.

Zeena, M.A., Rao, K., Rao, S., Subbakrishna, D.K., \& Prabhu, G.G. (1990). Stress coping in psychologically distressed and non distressed college students. Indian Journal of Psychological Medicine, 13, 63-70. 